\title{
Yogic Neti-Kriya Using Povidone Iodine: Can it have a Preventive Role Against SARS-CoV-2 Infection Gateway?
}

\author{
Phulen Sarma $^{1} \cdot$ Anusuya Bhattacharyya $^{2} \cdot$ Ajay Prakash $^{1} \cdot$ Hardeep Kaur $^{1} \cdot$ Manisha Prajapat $^{1}$. \\ Mukundam Borah $^{3} \cdot$ Subodh Kumar $^{1} \cdot$ Seema Bansal $^{1} \cdot$ Saurabh Sharma $^{1} \cdot$ Gurjeet Kaur $^{1} \cdot$ Harish Kumar $^{1}$. \\ Dibya Jyoti Sharma ${ }^{4} \cdot$ Karuna Kumar Das $^{5} \cdot$ Pramod Avti $^{6} \cdot$ Bikash Medhi $^{1}$
}

Received: 21 August 2021/Accepted: 18 September 2021/Published online: 17 October 2021

(C) Association of Otolaryngologists of India 2021

\begin{abstract}
During this COVID-19 pandemic, except steroid, none of the therapeutic measures have showed any evidence of efficacy. Traditionally jala-neti using lukewarm salted water remains a yogic way of maintaining upper airway hygiene. Saline irrigation decreases the concentration of inflammatory mediators (e.g. histamine, leukotriene etc.) in nasal secretions, reduces the severity and frequency of sinusitis, reduce need of antibiotic therapy and restores competency of nasal mucosa. Jala-neti is
\end{abstract}

Phulen Sarma and Anusuya Bhattacharyya contributed equally in the research work.

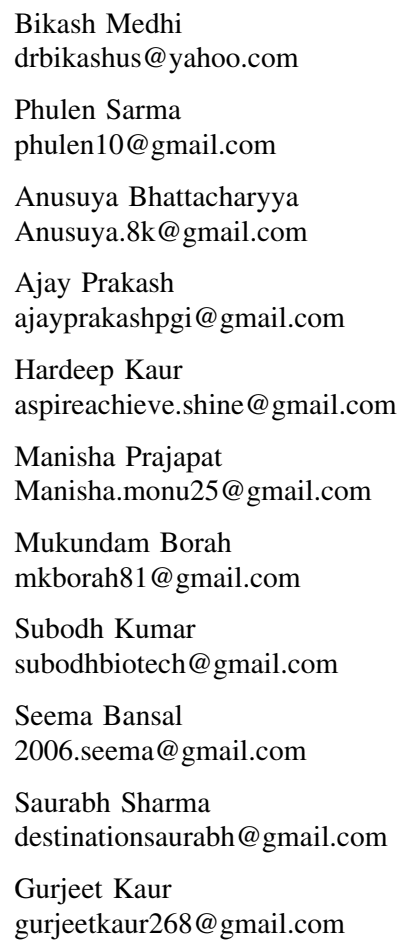

an integral part of six cleansing techniques of yogic kriyas practised in India since thousands of years. Jala-neti can clean the upper airways, prevents colonization of infectious agents, removes foreign bodies, prevents stasis of mucous and subsequently enhances the drainage of paranasal sinuses and maintain health. Regular practice of Jala neti improves nasal symptoms and overall health status of patients with sinusitis. Jala-neti sample can even be used for COVID-19 diagnosis. Povidone iodine (PVP-I) has been utilized as a time tested antimicrobial agent with broad spectrum coverage against wide range of bacteria and viruses. Anti-SARS-CoV-2 action of PVP-I was seen
Harish Kumar
hkumar98@gmail.com
Dibya Jyoti Sharma
Dibya.sharma@yahoo.com
Karuna Kumar Das
dr.karunadas@gmail.com
Pramod Avti
pramod.avti@gmail.com
1 Department of Pharmacology, PGIMER, Chandigarh Pin 160012, India
2 Department of Ophthalmology, Government Medical College and Hospital, Sector 32, Chandigarh, India
3 Department of Pharmacology, Gauhati Medical College and Hospital, Guwahati, Assam, India
4 Department of Internal Medicine, Silchar Medical College and Hospital, Silchar, Assam, India
5 Department of Anaesthesiology, Assam Medical College and Hospital, Dibrugarh, Assam, India
6 Department of Biophysics, PGIMER, Chandigarh, India 
at a concentration as low as $0.45 \%$. PVP-I is generally well tolerated upto $5 \%$, however nasal ciliotoxicity is reported at this concentration, however, this toxicity is not reported with lower concentrations $(1.25 \%$ and $0.5 \%)$. So, theoretically, by using neti-kriya with povidone iodine $(0.5-1 \%)$ as irrigation solution can combine and enhance the protection against COVID-19 and this can be an important armor in the fight against COVID-19. However, this hypothesis needs to be validated in real life clinical trial scenario before implementing.

Keywords Neti kriya · Jal neti · Povidone iodine · PVP-I · SARS-CoV-2 · COVID-19

\section{Background}

COVID-19 infection has become a global pandemic since it's onset in 2019 November. In this current scenario, scientists are trying their best to cope up with the situation with all possible way e.g. drug repurposing [1-8], identification of newer drug target [9-11], development of various diagnostic modalities [12], vaccine development [13], investigation of newer drug, virtual counseling/tele-medicine [14], maintaining social distancing, use of personal protective equipment (PPE), lifestyle modification (use of sanitizer, hand washing etc.) etc. and so on.

In ancient Indian yogic system, various kriyas are mentioned. These kriyas were integral part of day to day life of yogis (saints). These yogic kriyas are reported to boost immune system, improve respiratory capacity/ lung function, relieve stress, improve physical and mental strength and improve overall health [15]. Jala-neti" is an integral part of six cleansing techniques, forming an important aspects of "hatha-yoga" main aim being clearing upper respiratory tract [1]. Incidentally, the upper respiratory tract is the commonest first site of inoculation of SARS-CoV-2 [17]. The jala-neti procedure typically uses lukewarm salted water as irrigation solution [16].

Povidone iodine (PVP-I) has been utilized as a time tested antimicrobial agent with broad spectrum coverage against various bacteria and viruses at a concentration as low as $0.6 \%$ in vitro and clinical study [18, 19] and at concentration of $0.45 \%$ against SARS-CoV-2 [20-22].

In this article, we are discussing about jala-neti with povidone iodine irrigating solution as a therapeutic/preventive modality against COVID-19. By combining the jala-neti procedure and povidone iodine irrigation, we tend to enhance and optimize the beneficial effects of both the procedures as a weapon against COVID-19. The combination may be theoretically especially relevant for population at risk of COVID-19 e.g. health care worker, asymptomatic and mild to moderate COVID-19 population and to give insight how to practice the procedure in correct way in this ongoing global pandemic.

\section{Nasopharyngeal Localization of the Virus}

In human airways, highest expression of ACE2 (required for SARS-CoV-2 entry) in the nasal goblet cells and ciliated epithelium [23]. To better understand viral tropism, Sungnak et al. [24] evaluated the RNA expression of ACE2 and TMPRSS2 (Spike-protein priming protease) and found that both are expressed adequately in upper respiratory epithelium and nasal epithelial cells (especially goblet cells and ciliated-cells) display the highest ACE2 expression among of all the epithelial cells analyzed [24]. Similarly Hamming et al. [25] and $\mathrm{Wu}$ et al. [26] showed increased ACE2 expression in the basal layer of the "non-keratinizing squamous epithelium" in nasal and oral mucosa. Another study by Wu et al. [27] by using "single-cell RNA expression profiling" showed excessive ACE2 expression in nasal and mouth tissue along with co-expression of TMPRSS2 [27]. Based on the "public single-cell RNA-Seq datasets", Wu et al. [26] also found that pattern of expression of ACE2 was similar in nasal tissue, mouth, lung tissue and colon. Thus all these studies point towards to the fact that, nasopharyngeal localization through ACE receptor may serve as an important route of viral entry.

\section{Transmissibility of SARS-CoV-2}

SARS-CoV-2 virus has high transmission potential in all phases of disease: before, during and after the acute illness and it is characterized by presence of significant viral load in nasal as well as oral swab in all the phases of disease (more viral load in nasal swab ac compared to throat sample) both in asymptomatic as well as symptomatic patients suggesting equal transmission potential [23, 28]. So, theoretically, anything which decreases the viral load in oropharynx and nasopharynx can have some effect as a preventive and/or therapeutic agent and may decrease the transmission process.

In case of health care set up, especially in relation to aerosol-generating procedures, enhancement of transmission of virus can occur via transit through the nasal cavity and the upper respiratory tract receives a higher viral concentration in upper respiratory tract e.g. nasal cavity, sinuses etc. which may be evident upto $3 \mathrm{~h}$ [29]. Thus there is a need to explore other preventive measure to break the chain of virus transmission in the upper respiratory tract in addition to use of "personal protective equipment" especially to the health-care and frontline workers. 


\section{Role of Povidone Iodine in COVID-19}

Povidone iodine (PVP-I) is a time tested antimicrobial agent active against wide spectrum of bacteria and viruses (covers both enveloped as well as non-enveloped viruses including corona virus family) [19]. 1\% povidone iodine is already in use for viral conjunctivitis, especially adenoviral conjunctivitis [30-33] and can also be used in COVID-19 associated conjunctivitis [18, 19]. Povidone iodine sinus irrigations shows $43 \%$ post-treatment culture negativity result as compared to saline irrigation [34]. Again, occurrence of resistance is not a problem with PVP-I.

With special mention to its efficacy against corona virus, treatment of SARS-CoV for 2 min with PVP-I (concentration $0.23 \%$ and above, viral titer evaluated at $120 \mathrm{~s}$ ) [35] reduces its infectivity to "below detectable level" and the efficiency of PVP-I was similar to 70\% ethanol [35]. PVP-I gurgle/mouth wash $(0.23 \%$ for $15 \mathrm{~s}$ rapidly inactivate SARS-CoV, MERS-CoV and Influenza virus A) and nasal spray with essential iodine drops showed to be effective against different virus [36, 37]. Reduction of the viral infectivity by use of $1 \%$ PVP-I for (15 $\mathrm{s}$ for MARS-CoV and $1 \mathrm{~min}$ for SARS-CoV) has been proved by in vitro study [38]. Lowest concentration of PVP-I found to be effective against SARS-CoV-2 was 0.45\% [20-22].

IVIEW-1201 and IVIEW-1503, which are two in-situ gel forming formulations of PVP-I, consisting of $1.0 \%$ and $0.6 \%$ of Povidone-iodine [39], reduced SARS-CoV-2 viral titers to near or below the level of detection after 2 min of exposure. This also indicates that long acting nasal-spray can serve as a potential prophylactic measure against COVID-19 infection [39]. Another iodine preparation iodine $\mathrm{V}$ (essential Iodine drops containing elementaliodine $200 \mu \mathrm{g} / \mathrm{ml}$ ) also inhibited SARS-CoV-2 effectively in vitro. [40]

In otorhinolaryngology practice, application of PVP-I $(0.5 \%)$ by nasal route and oral route (gurgle) is recommended as a part of "SARS-CoV-2 a transmission reduction plan" [29]. PVP-I via nasal and oral route (gurgle) may serve as an effective preventive measure for close contacts of positive patient, subclinical asymptomatic carriers, mild symptomatic and "convalescent seroconverted patients" [23] due to its easy availability, accessibility, low cost. $1.25 \%$ PVP-I or below co concentration of PVP-I also not associated with inhibitory effect on ciliary clearance of nasal cavity as reported by previous data [41].

\section{Role of yogic Kriyas}

Physiological effects of yogic kriyas are already established [42]. Neti kriya is an integral part of the "six cleansing techniques/kriyas described in yogic literature forming most aspects of "hatha yoga" (a form of yoga that uses physical postures in combination with breathing and/ or meditation practices) [43] namely Kapalbhati, Trataka, Neti, Dhauti, Nauli and Basti kriya etc.[16, 44]. Hatha yoga is being practiced widely throughout the globe as an intervention among patients with long standing upper respiratory tract infection and also as a physical measure of "stress-reliever" especially in treatment drop out patients with wide acceptability [49].

Neti Kriya is based on the principle of clearing upper part of respiratory tract by using an irrigating fluid and it effectively removes the foreign bodies, prevents stasis of mucous and subsequently enhances drainage of paranasal sinuses and maintain health [16]. Neti is classified into two categories namely Jala-Neti and Sutra-Neti. Twice daily regular practice of Jala-neti for 6 week shows significant improvement of nasal symptoms and overall health status of patients with sinusitis [45]. It was found useful in chronic sinusitis in pediatric population while practiced using hypertonic saline $[46,47]$ who were not cured even after 1 months of standard treatment.

Evidence shows that, following saline solution irrigation (for $6 \mathrm{~h}$ after following single $15 \mathrm{~min}$ of treatment) [48], concentration of inflammatory mediators (e.g. histamine, leukotriene etc.) in the nasal secretions is significantly decreased. Daily nasal irrigation for a period of 6 months with a hypertonic saline solution reduced the severity of symptoms of sinusitis with reduced frequency of acute exacerbations along with need for antibiotic therapy both in patients $[49,50]$ and healthy adults [51] restored competency of nasal mucosa [16]. A systematic review already addressed the therapeutic effects of jala-neti in various systemic disease [49].

Regular practice of jala-neti in morning before doing any asana enhances cleaning upper respiratory tract secretions and decrease viral load as high-volume and high concentration of irrigating fluid administered locally directly to the nasal cavity. Jala Neti practice improves mucociliary clearance, decrease the inflammatory mediators and prevent blockage of sinus Ostia [52]. By improving sensitivity of nasal mucosa to allergen, the frequency of recurrence of upper respiratory tract infection is decreased by regular practice of jala neti [52]. Over all nasal cavity hygiene and its function is improved by regular jala neti alone by relieving nasal congestion, decrease the viscosity of mucous and keep nasal cavity moist [53]. 


\section{Traditional Method of Practice}

Traditional method of practice of Jala Neti is by using a "neti pot" which is filled with slightly warm saline water (commonly $2.5 \mathrm{gm}$ salt in $500 \mathrm{ml}$ of water) with recommended concentration of $2-3.5 \%$ for in nasal irrigation [54]. Other irrigation fluid used in traditional practice is milk, honey etc. and ideal time for practice is early morning [49]. Temperature of water/irrigating solution should to be checked before starting irrigation. Never to use plain water without salt as it may cause pain or vasovagal attack. The procedure should be conducted only after proper training with one person by side to the patient. The jal-neti procedure is not indicated in pediatric population. Among patients with chronic nasal bleeding, deformity of nose, proper precaution is to be taken and procedure to be practiced under expert guidance. Patient prone to ear infections should avoid jala-neti procedure [16]. [Video uploaded].

\section{Standardized Procedure of Neti Kriya}

The patient needs to sit comfortably in "kagasana" and to lean forward during the procedure. While performing the procedure, the nozzle of the neti-pot (prefilled with irrigation solution comprising of lukewarm water premixed with specified amount of salt) is to be inserted through one nostril. During the whole procedure normal breathing is to be continued through mouth. The irrigating fluid is allowed to enter through one nostril and to come out through other nostril [55]. In modern era, 4-size sterile rubber catheter is used in the jala neti practice [49]. Through both nostril average $200-300 \mathrm{ml}$ (half in each nostril) of solution has to be irrigated using neti kriya technique for effective result $[36,37]$. Whole procedure should to be routinely practiced $2 / 3$ times per day for better result. After neti, kapalbhati (Forceful exhalation of air which is followed by passive inhalation in rapid successions) is recommended to expel the residual irrigating fluid [49].

\section{Possible Adverse Event/Side Effect}

Although jala-neti is being practiced for thousands of years and is widely accepted as a safe procedure provided proper training is given before starting the practice. Mild risk of small amount of irrigating fluid entering into throat, mild stinging sensation etc. can be seen, but these improve over time when person is trained. Pediatric population should be avoided. Lower concentration of salt may cause burning sensation, nausea, cough etc. while higher concentration may hamper on mucociliary clearance in nasal cavity, pain, irritation and obstruction of nasal cavity [16]. Anosmia may occur as an adverse event (long term or temporary) of the intervention [56]. In the context of COVID-19, as there is risk of cross contamination, practioners should avoid using the same neti pot.

\section{Jala-Neti in the Context of COVID-19 Diagnosis}

Gupta et al. in their study [55] has described Jala neti as diagnostic modality for COVID-19 nasal sample collection. The author recommends that due to low sensitivity of the standard method of collection of nasopharyngeal sample collection technique [57] different other methods of sampling method have been evaluated (e.g. nasal wash [58], a sample taken by injecting and aspirating saline with the help of a syringe [58]) and jala neti may be a potential diagnostic method for detection [55].

\section{Jala Neti Using Povidone Iodine as Irrigating Fluid for SARS-CoV-2}

Theoretically, jala-neti with PVP-I may serve as potential physical measure in COVID-19 scenario by preventing colonization of virus in upper respiratory tract thus hamper subsequent involvement of lower respiratory tract and can serve as both preventive and therapeutic measure. At present various concentration of PVP-I is available such $10 \%$, $5 \%$ and $2 \%$ [59]. Lowest concentration found to be effective against SARS-CoV-2 was $0.45 \%$ [20-22].

One clinical study demonstrate that 5\% PVP-I was safe while delivered as a swab with only side effect reported as "vasovagal reaction during swab administration" [60]. However, published in vitro study demonstrated that $5 \%$ concentration showed toxicity against cilia [61, 62]. This nasal ciliotoxic effect was not observed with lower concentration with PVP-I e.g. 0.5\% [61, 62] Kramer et al. documented that there was "no suppression of ciliary activity" while applying $1.25 \%$ PVP-I as compared to $0.2 \%$ chlorhexidine (induced inhibition/reduction of ciliary activity to below the range of the physiological minimum) [63]. With effectiveness in killing the virus, low reported resistance, easy affordability of PVP-I and widespread acceptability of jala-neti, jala neti using low concentration of PVP-I (0.5-1\%) as irrigating agent may be used as both preventive and therapeutic physical measure to disinfect the sino-nasal cavity/ decrease viral load for SARS-CoV-2 in COVID-19 scenario [64, 65]. However it needs clinical validation. 


\section{Author's Experience}

The authors PS and AB practiced jala neti (lukewarm water with saline salt for cleaning their upper airway since last 15 years and with povidone iodine $0.5-1 \%$ intermittently since last 8 years for managing common respiratory ailments. This concentration of povidone iodine was tolerated well by both the authors over the period. Requirement of antibiotic for various nasopharyngeal infections were reduced for both the authors during this period. However, these findings need to be evaluated in the setting of a randomized controlled trial with adequate sample size for evaluation of generalisability of the findings.

\section{Conclusions}

Neti kriya a time tested physical measure to manage is an important yogic kriya which is practiced since thousands of years, used as therapy and preventive tool against upper respiratory tract with various modifications in modern practices. Jala-neti using PVP-I $(0.5-1 \%)$ as irrigation fluid can be used as a preventive/therapeutic measure against upper nasopharyngeal localization of the virus and different infectious agents including SARS-CoV-2. Thus there is a definite theoretical advantage of combining both these interventions. However, randomized controlled trials with adequate sample size are warranted to evaluate the external validity of these findings.

\section{References}

1. Bhattacharyya A, Kumar S, Sarma P, Kaur H, Prajapat M, Shekhar N et al (2020) Safety and efficacy of lopinavir/ritonavir combination in COVID-19: A systematic review, meta-analysis, and meta-regression analysis. Indian J Pharmacol 52:313-323

2. Sarma P, Kaur H, Kumar H, Mahendru D, Avti P, Bhattacharyya A et al (2020) Virological and clinical cure in COVID-19 patients treated with hydroxychloroquine: A systematic review and metaanalysis. J Med Virol 92:776-785

3. Prakash A, Singh H, Kaur H, Semwal A, Sarma P, Bhattacharyya A et al (2020) Systematic review and meta-analysis of effectiveness and safety of favipiravir in the management of novel coronavirus (COVID-19) patients. Indian J Pharmacol 52:414-421

4. Kaur H, Shekhar N, Sharma S, Sarma P, Prakash A, Medhi B (2021) Ivermectin as a potential drug for treatment of COVID-19: an in-sync review with clinical and computational attributes. Pharmacol Rep 73(3):736-749

5. Sarma P, Prajapat M, Avti P, Kaur H, Kumar S, Medhi B (2020) Therapeutic options for the treatment of 2019-novel coronavirus: An evidence-based approach. Indian J Pharmacol 52:1-5

6. Sarma P, Bhattacharyya A, Kaur H, Prajapat M, Prakash A, Kumar S et al (2020) Efficacy and safety of steroid therapy in
COVID-19: A rapid systematic review and Meta-analysis. Indian J Pharmacol 52:535-550

7. Bhattacharyya A, Sarma P, Kaur H, Medhi B (2021) Hydroxychloroquine in Nonhospitalized Adults With Early COVID-19. Ann Intern Med 174:434

8. Kaur H, Sarma P, Bhattacharyya A, Prajapat M, Kumar S, Prakash A et al (2021) Folic acid as placebo in controlled clinical trials of hydroxychloroquine prophylaxis in COVID-19: Is it scientifically justifiable? Med Hypotheses 149:110539

9. Prajapat M, Shekhar N, Sarma P, Avti P, Singh S, Kaur H et al (2020) Virtual screening and molecular dynamics study of approved drugs as inhibitors of spike protein S1 domain and ACE2 interaction in SARS-CoV-2. J Mol Graph Model 101:107716

10. Prajapat M, Sarma P, Shekhar N, Prakash A, Avti P, Bhattacharyya A et al (2020) Update on the target structures of SARSCoV-2: A systematic review. Indian J Pharmacol 52:142-149

11. Prajapat M, Sarma P, Shekhar N, Avti P, Sinha S, Kaur H et al (2020) Drug targets for corona virus: A systematic review. Indian J Pharmacol 52:56-65

12. Mahendiratta S, Batra G, Sarma P, Kumar H, Bansal S, Kumar S et al (2020) Molecular diagnosis of COVID-19 in different biologic matrix, their diagnostic validity and clinical relevance: A systematic review. Life Sci 258:118207

13. Kumar S, Sarma P, Kaur H, Prajapat M, Bhattacharyya A, Avti P et al (2021) Clinically relevant cell culture models and their significance in isolation, pathogenesis, vaccine development, repurposing and screening of new drugs for SARS-CoV-2: a systematic review. Tissue Cell 70:101497

14. Hazarika M, Das B, Das S, Baruah A, Sharma N, Barua C et al (2021) Profile of distress callers and service utilisation of telecounselling among the population of Assam, India: an exploratory study during COVID-19. Open J Psychiatry Allied Sci 12:7-12

15. Woodyard C (2011) Exploring the therapeutic effects of yoga and its ability to increase quality of life. Int J Yoga 4:49-54

16. Meera S, Vandana Rani M, Sreedhar C, Robin DT (2020) A review on the therapeutic effects of NetiKriya with special reference to JalaNeti. J Ayurveda Integr Med 11:185-189

17. Peiris JSM, Chu CM, Cheng VCC, Chan KS, Hung IFN, Poon LLM et al (2003) Clinical progression and viral load in a community outbreak of coronavirus-associated SARS pneumonia: a prospective study. Lancet Lond Engl 361:1767-1772

18 Sarma P, Kaur H, Medhi B, Bhattacharyya A (2020) Letter to the editor: Possible role of topical povidone iodine in case of accidental ocular exposure to SARS-CoV-2. Graefes Arch Clin Exp Ophthalmol Albrecht Von Graefes Arch Klin Exp Ophthalmol 258(11):2575-2578

19 Sarma P, Kaur H, Medhi B, Bhattacharyya A (2020) Possible prophylactic or preventive role of topical povidone iodine during accidental ocular exposure to 2019-nCoV. Graefes Arch Clin Exp Ophthalmol Albrecht Von Graefes Arch Klin Exp Ophthalmol. 258(11):2563-2565

20. Anderson DE, Sivalingam V, Kang AEZ, Ananthanarayanan A, Arumugam H, Jenkins TM et al (2020) Povidone-Iodine Demonstrates Rapid In Vitro Virucidal Activity Against SARSCoV-2, The Virus Causing COVID-19 Disease. Infect Dis Ther 9:669-675

21. Bidra AS, Pelletier JS, Westover JB, Frank S, Brown SM, Tessema B (2020) Comparison of In Vitro Inactivation of SARS CoV-2 with Hydrogen Peroxide and Povidone-Iodine Oral Antiseptic Rinses. J Prosthodont Off J Am Coll Prosthodont 29:599-603

22. Bidra AS, Pelletier JS, Westover JB, Frank S, Brown SM, Tessema B (2020) Rapid In-Vitro Inactivation of Severe Acute Respiratory Syndrome Coronavirus 2 (SARS-CoV-2) Using 
Povidone-Iodine Oral Antiseptic Rinse. J Prosthodont Off J Am Coll Prosthodont 29:529-533

23. Wei WE, Li Z, Chiew CJ, Yong SE, Toh MP, Lee VJ (2020) Presymptomatic Transmission of SARS-CoV-2 - Singapore, January 23-March 16, 2020. MMWR Morb Mortal Wkly Rep 69:411-415

24. Sungnak W, Huang N, Bécavin C, Berg M, Lung H. SARS-CoV2 Entry Genes Are Most Highly Expressed in Nasal Goblet and Ciliated Cells within Human Airways. Available from: https://arxiv.org/ftp/arxiv/papers/2003/2003.06122.pdf.

25 Hamming I, Timens W, Bulthuis MLC, Lely AT, Navis GJ, van Goor H (2004) Tissue distribution of ACE2 protein, the functional receptor for SARS coronavirus. A first step in understanding SARS pathogenesis. J Pathol 203:631-637

26. Wu C, Zheng M. Single-Cell RNA Expression Profiling Shows that ACE2, the Putative Receptor of Wuhan 2019-nCoV, Has Significant Expression in the Nasal, Mouth, Lung and Colon Tissues, and Tends to be Co-Expressed with HLA-DRB1 in the Four Tissues. Preprints; 2020. Available from: https://www.preprints.org/manuscript/202002.0247/v1, accessed on March 29, 2020.

27. Single-cell RNA expression profiling shows that ACE2, the putative receptor of COVID-2019, has significant expression in nasal and mouth tissue, and is co-expressed with TMPRSS2 and not co-expressed with SLC6A19 in the tissues. 2020. Available from: https://www.researchsquare.com/article/rs-16992/v1, accessed on March 29, 2020.

28. Zou L, Ruan F, Huang M, Liang L, Huang H, Hong Z et al (2020) SARS-CoV-2 Viral Load in Upper Respiratory Specimens of Infected Patients. N Engl J Med Massachusetts Medical Soc 382:1177-1179

29. Khan MM, Parab SR, Paranjape M (2020) Repurposing 0.5\% povidone iodine solution in otorhinolaryngology practice in Covid 19 pandemic. Am J Otolaryngol 41:102618

30. Clement C, Capriotti JA, Kumar M, Hobden JA, Foster TP, Bhattacharjee PS et al (2011) Clinical and antiviral efficacy of an ophthalmic formulation of dexamethasone povidone-iodine in a rabbit model of adenoviral keratoconjunctivitis. Invest Ophthalmol Vis Sci 52:339-344

31. Pinto RDP, Lira RPC, Abe RY, Zacchia RS, Felix JPF, Pereira AVF et al (2015) Dexamethasone/Povidone Eye Drops versus Artificial Tears for Treatment of Presumed Viral Conjunctivitis: A Randomized Clinical Trial. Curr Eye Res 40:870-877

32. Kovalyuk N, Kaiserman I, Mimouni M, Cohen O, Levartovsky S, Sherbany H et al (2017) Treatment of adenoviral keratoconjunctivitis with a combination of povidone-iodine $1.0 \%$ and dexamethasone $0.1 \%$ drops: a clinical prospective controlled randomized study. Acta Ophthalmol (Copenh) 95:686-692

33. Pepose JS, Narvekar A, Liu W, Haque R (2019) A randomized controlled trial of povidone-iodine/dexamethasone ophthalmic suspension for acute viral conjunctivitis. Clin Ophthalmol Auckl NZ 13:535-544

34. Lee VS, Pottinger PS, Davis GE (2020) Tolerability and effectiveness of povidone-iodine or mupirocin versus saline sinus irrigations for chronic rhinosinusitis. Am J Otolaryngol 41:102604

35. Kariwa H, Fujii N, Takashima I (2006) Inactivation of SARS Coronavirus by Means of Povidone-Iodine, Physical Conditions and Chemical Reagents. Dermatol Basel Switz 212(Suppl 1):119-123

36. Eggers M, Koburger-Janssen T, Eickmann M, Zorn J (2018) In Vitro Bactericidal and Virucidal Efficacy of Povidone-Iodine Gargle/Mouthwash Against Respiratory and Oral Tract Pathogens. Infect Dis Ther 7:249-259

37. Eggers M, Eickmann M, Zorn J (2015) Rapid and Effective Virucidal Activity of Povidone-Iodine Products Against Middle
East Respiratory Syndrome Coronavirus (MERS-CoV) and Modified Vaccinia Virus Ankara (MVA). Infect Dis Ther 4:491-501

38. Kampf G, Todt D, Pfaender S, Steinmann E (2020) Persistence of coronaviruses on inanimate surfaces and their inactivation with biocidal agents. J Hosp Infect Elsevier 104:246-251

39. Liang B, Yuan X, Wei G, Wang W, Zhang M, Peng H, et al. InVivo Toxicity Studies and In-Vitro Inactivation of SARS-CoV-2 by Povidone-iodine In-situ Gel Forming Formulations. Microbiology; 2020 May. Available from: http://biorxiv.org/lookup/doi/ https://doi.org/10.1101/2020.05.18.103184, accessed on May 22, 2021.

40. Zoltán K. In Vitro Efficacy of "Essential Iodine Drops" Against Severe Acute Respiratory Syndrome-Coronavirus 2 (SARS-CoV2). Pharmacology and Toxicology; 2020 Nov. Available from: http://biorxiv.org/lookup/doi/

https://doi.org/10.1101/2020.11.07.370726, accessed on May 22, 2021.

41. Reimer K, Wichelhaus TA, Schäfer V, Rudolph P, Kramer A, Wutzler P et al (2002) Antimicrobial effectiveness of povidoneiodine and consequences for new application areas. Dermatol Basel Switz 204(Suppl 1):114-120

42. Patra SK (2017) Physiological effect of kriyas: Cleansing techniques. Int J Yoga - Philosop Psychol Parapsychol 5:3-5

43. Vollbehr NK, Bartels-Velthuis AA, Nauta MH, Castelein S, Steenhuis LA, Hoenders HJR et al (2018) Hatha yoga for acute, chronic and/or treatment-resistant mood and anxiety disorders: A systematic review and meta-analysis. PloS One 13:e0204925

44. R. Bahadur, S. Chandra Vasu The gheranda samhita. The training of the physical body: chapter 1, verse 51 (1st ed.), Chaukhamba Sanskrit Pratishthan, Varanasi (2003), p. 18.

45. Tomooka LT, Murphy C, Davidson TM (2000) Clinical study and literature review of nasal irrigation. Laryngoscope 110:1189-1193

46. Shoseyov D, Bibi H, Shai P, Shoseyov N, Shazberg G, Hurvitz H (1998) Treatment with hypertonic saline versus normal saline nasal wash of pediatric chronic sinusitis. J Allergy Clin Immunol 101:602-605

47. Lin SY, Baugher KM, Brown DJ, Ishman SL (2015) Effects of nasal saline lavage on pediatric sinusitis symptoms and diseasespecific quality of life: a case series of 10 patients. Ear Nose Throat J 94:E13-18

48. Georgitis JW (1994) Nasal hyperthermia and simple irrigation for perennial rhinitis. Changes in inflammatory mediators Chest 106:1487-1492

49. Meera S, Vandana Rani M, Sreedhar C, Robin DT. A review on the therapeutic effects of Neti Kriya with special reference to Jala Neti. J Ayurveda Integr Med 2019. Available from: http://www.sciencedirect.com/science/article/pii/ S0975947617306216, accessed on March 29, 2020.

50. Rabago D, Zgierska A, Mundt M, Barrett B, Bobula J, Maberry R (2002) Efficacy of daily hypertonic saline nasal irrigation among patients with sinusitis: a randomized controlled trial. J Fam Pract 51:1049-1055

51. Tano L, Tano K (2004) A daily nasal spray with saline prevents symptoms of rhinitis. Acta Otolaryngol (Stockh) 124:1059-1062

52. Kumara H, Minrupa B, Karunaratne S, Karunaratne H. Yoga Therapy for Immunomodulation (Prevent \& Cure) of COVID-19. 2021.

53. 460215918rani.pdf. Available from: http://repository-tnmgrmu. ac.in/10176/1/460215918rani.pdf, accessed on May 9, 2021.

54. Achilles N, Mösges R (2013) Nasal Saline Irrigations for the Symptoms of Acute and Chronic Rhinosinusitis. Curr Allergy Asthma Rep 13:229-235 
55 Gupta A, Gupta B (2020) Jal Neti Sample for COVID Detection: A Novel Hypothesis. Indian J Otolaryngol Head Neck Surg Off Publ Assoc Otolaryngol India 73(1):104-106

56. Burton MJ, Clarkson JE, Goulao B, Glenny A-M, McBain AJ, Schilder AG et al (2020) Antimicrobial mouthwashes (gargling) and nasal sprays administered to patients with suspected or confirmed COVID-19 infection to improve patient outcomes and to protect healthcare workers treating them. Cochrane Database Syst Rev. https://doi.org/10.1002/14651858.CD013626.pub2

57. Desmet T, Paepe PD, Boelens J, Coorevits L, Padalko E, Vandendriessche $\mathrm{S}$, et al. Combined oropharyngeal/nasal swab is equivalent to nasopharyngeal sampling for SARS-CoV-2 diagnostic PCR. BMC Microbiol 2021; 21. Available from: https://www.ncbi.nlm.nih.gov/pmc/articles/PMC7820523/, accessed on May 22, 2021.

58. Calame A, Mazza L, Renzoni A, Kaiser L, Schibler M (2021) Sensitivity of nasopharyngeal, oropharyngeal, and nasal wash specimens for SARS-CoV-2 detection in the setting of sampling device shortage. Eur J Clin Microbiol Infect Dis 40:441-445

59. Chundamala J, Wright JG (2007) The efficacy and risks of using povidone-iodine irrigation to prevent surgical site infection: an evidence-based review. Can J Surg J Can Chir 50:473-481

60. Phillips M, Rosenberg A, Shopsin B, Cuff G, Skeete F, Foti A et al (2014) Preventing surgical site infections: a randomized, open-label trial of nasal mupirocin ointment and nasal povidoneiodine solution. Infect Control Hosp Epidemiol 35:826-832
61. Kim JH, Rimmer J, Mrad N, Ahmadzada S, Harvey RJ (2015) Betadine has a ciliotoxic effect on ciliated human respiratory cells. J Laryngol Otol Cambridge University Press 129:S45-50

62. Ramezanpour M, Smith JLP, Psaltis AJ, Wormald PJ, Vreugde S (2020) In vitro safety evaluation of a povidone-iodine solution applied to human nasal epithelial cells. Int Forum Allergy Rhinol 10:1141-1148

63. Kramer A, Below H, Behrens-Baumann W, Müller G, Rudolph P, Reimer K (2002) New aspects of the tolerance of the antiseptic povidone-iodine in different ex vivo models. Dermatol Basel Switz 204(Suppl 1):86-91

64. Mady LJ, Kubik MW, Baddour K, Snyderman CH, Rowan NR (2020) Consideration of povidone-iodine as a public health intervention for COVID-19: Utilization as "Personal Protective Equipment" for frontline providers exposed in high-risk head and neck and skull base oncology care. Oral Oncol 105:104724

65. Moein ST, Hashemian SMR, Mansourafshar B, Khorram-Tousi A, Tabarsi P, Doty RL. Smell dysfunction: a biomarker for COVID-19. Int Forum Allergy Rhinol 2020. Available from: https://www.ncbi.nlm.nih.gov/pmc/articles/PMC7262123/, accessed on May 9, 2021.

Publisher's Note Springer Nature remains neutral with regard to jurisdictional claims in published maps and institutional affiliations. 